\title{
Creating Space for Critical Literacy in Extensive Reading Class:
}

\section{A Practitioner's Account}

\author{
CHEN Yan-ru \\ Jiangxi Normal University, Nanchang, China
}

\begin{abstract}
English for critical literacy has long been neglected in Chinese EFL (English as a Foreign Language) context. This paper is a personal narrative that explores my experience of creating space for critical literacy in EFL extensive reading class, illustrated by a thematic reading unit that I have developed, and discusses the possibility and challenges of develping critical literary in reading instruction.
\end{abstract}

Keywords: critical literacy, critical reading, extensive reading

\section{Introduction}

In the adapted version of Stephen Ball's Models of English as a School Subject, four aspects of English teaching are labeled: English as skills, English as a great literary tradition, English for personal growth, and English for critical literacy (Monaghan, 2007). English as skills emphasizes equipping students with literary skills to participate effectively in society, particularly the mastery of the technical procedures of decoding and encoding; English as great literary tradition emphasizes the significance of giving students access to the valued literary canon of a culture; English for personal growth emphasizes personal and creative making of meaning through reading and writing; English for critical literacy emphasizes exposing and critiquing social values that reside in all texts.

The division of the four aspects is by no means clear-cut in real classroom. As Monaghan (ibid) has noted, most classrooms reflect the four aspects in differing mixtures. However, the story may be different in China. In Chinese context, the prevailing attitude toward English teaching and learning is to treat English as a skill to master. This mentality is reflected in the English Language Teaching Syllabus for English majors in Institutes of Higher Learning published in 2000. In the syllabus, skill-based English courses occupy $67 \%$ of the total courses, content-based English courses 15\%, and relevant content-based courses 18\% (WANG \& HE, 2009). Moreover, for Non-English majors and English majors in China, skills to pass high-stake exams such as CET (College English Test) or TEM (Test for English Majors) are crucial largely because CET and TEM scores are highly valued in the job market. This result in the tension that university English language teachers in China are confronted with between teaching the book and educating the person, as Wette and Barkhuizen (2009) point out.

Of the four orientations, critical literacy is the most neglected one in EFL context. According to ZHANG (2008), the major reason for such neglect in EFL reading classroom is that it is commonly held that reading

CHEN Yan-ru, lecturer, master, School of Foreign Languages, Jiangxi Normal University. 
involves extracting objective meaning encoded in texts and thus learners' reading development means developing decoding and vocabulary skills. More often than not, this reading-as-a-skill orientation results in a reductionist reading pedagogy and consequently students are deprived of opportunities to exercise higher-thinking ability to read texts critically. However, the ability to read texts critically is intertwined with the ability to read the world as all texts are not neutral, but embody social values and position and influence them as readers. Developing critical literacy is significant for the learner to make sense of the world and become agents of change for social justice.

A question arises: how can a reading teacher incorporate the critical reading pedagogy in the EFL context? In this essay, I will explore my experience of creating space for critical literacy in EFL extensive reading class, with a focus on a thematic reading unit that I have developed. The purpose is to make a case for the possibility of critical literary in reading instruction.

\section{Key Terms}

\section{Critical Literacy}

Critical theories of literacy are informed by critical social theory, which hold that society is a site where different social groups constantly contest for the possession of knowledge, power, status, and material resources (Morgan, 1997). Certain social groups have historically gained controlled over ideologies, institutions, and practices of their society and therefore have achieved and maintained their dominant position. One way of gaining control is through the particular uses of language to construct, circulate, and promote a certain ideology and advance the interests of the dominant group. The key assumption underlying the critical social theory is that reality, identities, and relationships in texts are always constructed in texts, and yet because dominant ways of construction are rarely challenged or questioned, people come to see them as the naturalized ways of life and thinking. Therefore, critical literacy is largely about examining cultural and ideological assumptions embedded in texts so to achieve a better understanding of the causes of inequities and exercise agency to transform the world. As McDaniel (2006) puts it, "critical literacy transcends conventional notions of reading and writing to incorporate critical thinking, questioning, and transformation of self and/or one's world" (p. 5).

\section{Critical Reading}

The notion of critical literacy stresses the social and cultural dimension of "literary events", the communicative events mediated by sociocultural values and attitudes. All these activities are social behaviours, ways of achieving specific social purposes in a particular socio-cultural context. Compared to critical literacy, critical reading has a narrower scope. Wallace (2003) states that critical literacy involves more macro-understanding of literary practices in wider sociocultural contexts and critical reading involves more micro-interaction between the text producer, the texts, and the text reader in immediate, specific social settings. Wallace's stance on critical reading also signals her stance on what reading is. Compared to the commonly held view of reading as a individual and cognitive process, Wallace (2003) views reading as a "social, critical process" (p. 1). The social nature of reading is because the act of text production and consumption does not occur in vacuum, but occurs in context, both in the immediate context of situation and in the wider cultural context, and the participants involved in the process, namely, writers and readers, are also influenced by social context. Therefore, reading is a dynamic interaction between the writer, the text, and the reader. Critical reading is to take 
a critical stance toward the text, which, as a social construct, reflects institutional and wider social assumptions. It involves "critiquing not just the logic, argument or sentiments expressed in texts, but the ideological assumptions underpinning them" (ibid, p. 42). In language classroom, critical reading pedagogy is less concerned with sepcific strategies to enhance comprehension, but more concerned with encouraging learners to adopt a position to the text. Promoting adopting a critical perspective is one of the primary goals of critical reading pedagogy. In language learning, this goal is intertwined with another goal, that is to raise students' critical language awareness, a heightened consciousness of how the writer mobilizes lexico-grammar choices function to represent the world and position the readers and manipulate readers' perceptions of the text.

\section{Procedures and Problems in my Teaching Context}

In this section, I will look back at my experience of bringing a critical dimension to my extensive reading class and discuss my practices and the difficulties that I have experienced.

Like most extensive reading courses for English majors at tertiary level in China, the extensive reading course in the institution where I work is a marginalized course, which only occupies the slot of a two-hour session every week. Although the importance of reading is widely acknowledged by teachers and learners, extensive reading has not been given fair share of attention. Compared to intensive reading course, extensive reading is more like a step-daughter. Intensive reading feature more prominently in the whole English curriculum, spanning the four years and consuming more class hours. Extensive reading courses are offered to freshmen and sophomores. One of the reasons for the unequal status is that the tests of intensive reading in my institution center around what is covered in class and the tests of extensive reading are more about reading competence, not closely related with the reading textbook. This gives extensive reading teachers more autonomy to implement their teaching agendas. During my first years of my teaching in the institution, I have prioritized teaching freshmen strategies to read for gist, motivated by the intention to change their habit of reading for details developed from their previous reading experience. The strategies, despite some initial resistance, are well-received by the students on the whole, as they come to experience the effect of efficiency of the strategies to increase the reading speed. However, with the passage of time, I grew increasingly uncertain about my agenda. I began to question the value of fast reading strategies: what is the point of reading fast if you do not reap much benefits from the reading? My dissatisfaction with the textbook also grew. It contains mainly expository texts that are not closely related to students' life and therefore much of the class time is devoted to locate information. Although the textbook contains some texts on culture, they are mainly about cultural differences about wedding ceremony, table manners, and body language. I began to ask myself "what is the educational value of my reading class? How can I link what we read to the real world? How can the students use the text in a deeper way?" The concept of critical reading have been haunting me, although I know very little about what it actually means. Due to lack of access to relevant literature on this topic, I relied on my intuition developed from my own learning, reading, and social experience. I decided to incorporate elements on cultural studies, some common issues that cut across cultures and exert influence on our personal life. I started to reflect on my own experience and decide to develop a theme-based unit on the issue of gender. In my class, girls dominate and boys seem to be the marginalized minority. Gender issues seem not to be one of the concerns for the girls. However, from my personal experience, I knew what social pressures may exert on my roles and influence my perceptions and my decisions as a woman, 
at domestic and public settings. I decided to design an unit on gender issues since these are issues that both my students and I can relate to and draw on personal experiences and perspectives to discuss. Some of the texts chosen are from the book Academic Encounters: Life in Society (Reading, Study Skills, Writing) edited by Kristine Brown and Susan Hood, published by Cambridge University Press in 2005. One chapter in their edition is about Gender and Society, which addresses various gender issues, like the socialization of girls and boys, gender inequality at work, sexual harassment, gender stereotypes in media representation. These texts mainly serve as conceptual scaffolding to open their vision about what perspective sociology has offered on gender issue. When we read the articles together in class, I asked students questions to explore their own beliefs and also questions to examine the effects of grammatical choices. For instance, when we approached the text Balancing Home and Work, I asked students "We know balance is a verb. So who need to balance home and work? What's the meaning of the word balance? Can we use other words than balance? Such as integrate?" By using these questions, students began to examine the assumptions embedded in the title, but also explore their own assumptions about gender roles.

After preparing them with a new understanding of gender issues and also some technical language to talk about gender issues, I asked them to analyze texts, two advertisements targeting male and female audience respectively, and two fairy tales. The verbal elements of the advertisements are short and simple: "It is not your shoes. It is not your car. It is not your music. It is the watch that most tells who you are" in one ad and "It is not your handbag. It is not your neighbourhood. It is not your boyfriend. It is your watch that tells most about who you are". in the other ad. I first asked them questions about the purpose and the target audience of the two texts. Followed by a series of question: "Does the word 'your' describe the same relationship in the two texts? What is the relationship between you and shoes, car, music? What is the relationship between you and the neighborhood and the boyfriend?". These questions were meant to encourage students to examine the linguistic choices and underlying beliefs, the grammatical relationship between "your" and the head nouns. It is surprising for them to discover that males own things, while females are defined by relationship, as "you" cannot do things to the boyfriend or community as you do to the things you own. When analyzing the two fairy tales, one classic and one modern fairy tale, I asked them to observe the lexical collocation in the two texts concerning male and female roles. After the reading task, I asked the students to rewrite the classic fairy tale and brought their rewriting to the classroom to share. Overall my students responded positively to this kind of teaching. Some said that my teaching broadened their mind and alerted them to the functions of language. However, some students also reported that they sometimes had difficulty in following my steps and answering the questions, many of which were tough questions with no ready-made answers "locatable" in the text. The difficulty that they experienced in my class sometimes resulted in a feeling of ineffective learning. One of the students even commented after class, "Ms. CHEN, I need to read very closely the texts before I come to the class to follow your lead, so is it still extensive reading?" In addition to the frustration and puzzles of the students, I also found that my interest and my belief in some issues may not be shared by some of my students. When students say something that are different from my assumptions, I usually rush to show my disapproval or totally ignore the alternative views. In retrospect, the authoritarian role that I subconsciously assume may have detrimental effect on encouraging students to bring in their perspectives to the classroom. 


\section{Discussion}

Reflecting on my own experience, I have found that several factors play an important role in creating space for critical pedagogy in reading curriculum. One factor is concerned with what texts to analyze. Although no text is value-free, texts related to some general social issues are more appropriate to be used to promote critical reading and create space for critical literacy in the classroom. Teachers can draw on a wide range of authentic texts, including advertisements and fairy tales, which students encounter in their real-life reading but seldom touch upon in language classroom. These texts of everyday life are known as "community texts" (Luke et al., 2001, p. 113), which shape and are shaped by a particular context. For English majors in my context, these texts do not pose much difficulty linguistically, which allows them more cognitive resources to attend to the implied meaning of the language. Another aspect is how to analyze texts. Intuitively I have found the appropriate way, that is, to examine the linguistic choices that reflect social and cultural assumptions embedded in the text. However, my analysis is not systematic and comprehensive. Wallace (2003) states that Hyllidayan framework of systemic functional grammar is an effective analytical tool, which can be adapted to workable framework for second language learners and that "getting to the 'hidden grammar' is the ultimate goal of critical reading pedagogy" (p. 33). The examples of examining the word order in "balancing home and work" and the relationship of "your" and head nouns clearly demonstrate some features of the grammar are less accessible to consciousness, but reflect hidden cultural assumptions. The third factor is how to build interpretative community. This largely depends on the role of the teacher plays. A tension will be felt by educators who want to encourage multiple perspectives and at the same assess the acceptability of students' interpretations. Wallace suggests that

what we can do is to make our aims in teaching and our ideological and political leanings as explicit as possible; aim to make our practice visible. Importantly, we can invite challenge to our positions as much as to the ideologies of the texts studied in class. $(2003$, p. 76)

\section{Conclusion}

My experience has illustrated that it is possible to enhance critical language awareness by encouraging students to explore the relationship between the text and underlying ideology. I do acknowledge that promoting critical literacy is a challenging task for EFL teachers in a skill-oriented cultural context. However, for any teachers who aim to promote social justice, it is their responsibility to lead the learners on the way to becoming a better reader of the text and the world that they live in.

\section{References}

Luke, A., O’Brien, J., \& Comber, B. (2001). Making community texts objects of study. In H. Fehring \& P. Green (Eds), Critical literacy. Delaware: International Reading Association.

McDaniel, C. (2006). Critical literacy: A way of thinking, a way of life. New York: Peter Lang Publishing.

Monaghan, F. (2007). English in the curriculum. In N. Mercer, J. Swann, \& B. Mayor (Eds.), Learning English. London: Routledge. Morgan, W. (1997). Critical literacy in the classroom: The art of the possible. London, New York: Routledge.

WANG, Y., \& HE, X. (2009). Intensive reading: Fifty years of English teaching in China. CELEA Journal, 29(1), 79-83.

Wallace, C. (2003). Critical reading in language education. New York: Palgrave Macmillan.

Wette, R., \& Barkhuizen, G. (2009). Teaching the book and educating the person: Challenges for university English language teachers in China. Asia Pacific Journal of Education, 29(2), 195-212. 
ZHANG, L. J. (2008). EFL teacher professional development through critical reading pedagogy: Meeting the challenges in the Asian classroom. In Q. F. WEN (Ed.), Proceedings of the 5th International Conference on ELT in China cum the 1th International Conference of Applied Linguistics Association of China. Beijing, China: Foreign Language Teaching and Research Press. 